\title{
Book review: The Man behind "Degree Celsius": A Pioneer in Investigating the Earth and its Changes
}

\author{
David S. Chapman ${ }^{1, *}$ \\ ${ }^{1}$ Department of Geology and Geophysics, University of Utah, Utah, USA \\ * retired \\ Correspondence: David S. Chapman (david.chapman@utah.edu) \\ Published: 19 March 2018
}

Ekman, M.: The Man behind "Degree Celsius": A Pioneer in Investigating the Earth and its Changes, Summer Institute for Historical Geophysics, 159 pp., ISBN: 978-952-93-77329, EUR 22.00, 2016.

The Man behind "Degree Celsius": A Pioneer in Investigating the Earth and its Changes by Martin Ekman is a gem of a little book. It effectively describes not only the scientific discoveries and contributions of Anders Celsius after whom the temperature scale is named, but also how science was conducted in Sweden 300 years ago, the oversized impact of the little university town of Uppsala and its university founded in 1477 , and the critical importance of making careful geophysical observations in space and time in advancing knowledge about our Earth.

The book starts, not in the year 1701 with the birth of Anders Celsius, but three generations earlier with another Celsius, Anders' grandfather Magnus Celsius. By doing so, Ekman effectively traces the importance of a scientific family's genealogy and successive inheritance within the Celsius family of academic positions as astronomers.

Anders Celsius' career started with interests in mathematics, but soon turned to astronomy, which at that time encompassed other fields of geophysics. As early as 1722, Celsius showed a predilection for making and chronicling geophysical observations and had begun to accumulate important time series of meteorological data including temperature and pressure. In 1730, at age 29, and after years of unpaid work as an assistant, Celsius was appointed professor of astronomy at the University of Uppsala. With his professorship came an opportunity for a tour abroad. Celsius' tour involved Germany, Italy, France, and England, but was most influenced by his connection to the Paris Observatory, where science was relatively advanced. In Paris he also became involved with the controversy on the shape of the Earth between Newton (who argued for an oblate spheroid flattened at the poles) and Cassini (who argued for a prolate spheroid flattened at the Equator). The controversy was to be solved by making meridian arc measurements at separated latitudes, one at the Equator and the other at a northern site. Celsius suggested a northern Swedish site near the Gulf of Bothnia and was immediately made a member of the expedition. The book goes into considerable, but rewarding, detail on the expedition, including challenges of travelling and living in the north in the early 1700 s, the meticulous triangulation measurements, and pendulum gravity measurements. This expedition, as we now know, confirmed that Newton was correct.

Back at home in Uppsala, Celsius assumed his role of professor of astronomy and raised money to build the Uppsala Observatory, still standing today. He equipped the observatory with angle instruments, telescopes, thermometers, barometers, magnetic compasses, and in particular a pendulum clock made in London by "the best clock-maker in $\mathrm{Eu}$ rope".

A series of chapters of the book are devoted to broad geophysical studies Celsius conducted that we do not normally associate with his name: precise latitude and longitude mapping in particular for the Uppsala Observatory; measuring gravity with his pendulum clock to study the flattening of the Earth; uplift of the land on the Swedish coast; sea level in relation to atmospheric pressure; and magnetic variations in time related to northern lights. Many of these studies, such as mapping, were undertaken to serve the needs of society, and thus one could call Celsius an early practitioner of applied geophysics.

Ekman has also peppered his book with fascinating details that will resonate with multiple readers. Many who have lost data due to inadequate backup will empathize with Cel- 
sius' colleague Wargentin, who around 1741 was travelling by horse and carriage from Uppsala to Stockholm and had a case stolen. The case contained his meticulous work on tables for eclipses of the moons of Jupiter and cost Wargentin an extra 2 years in recomputing his tables.

Some readers might be impatient to find they have to wait 106 pages before they get a discussion of Celsius' development of the temperature scale named after him, but it is Ekman's goal to show the full impact of Celsius' work as astronomer, geodesist, and applied geophysicist. The description of the developments leading to the Celsius scale in ca. 1741 is quite instructive and indicative of Celsius' general experimental approach. First came the realization of inadequacies of previous temperature scales, in particular the requirement of two fixed temperature points and a scale dividing the points into units. The freezing point of water was commonly used as one fixed point, but scientists differed on the other, warmer fixed point: the maximum heat in London by Hawksbee in England, and the heat of the human body by Roemer in Denmark and Fahrenheit in Holland and Germany. Delisle in France used the boiling point of water as one fixed point but the coolness of the basement of the Paris Observatory as the other fixed point.

Celsius, on the other hand, focused on the freezing and boiling points of water as fixed points and systematically investigated factors that could affect their temperatures. He used a snow-water mixture as the freezing point of water. "I have put the thermometer in the melting snow ... not only when there has been a thaw. Also, when there has been strong winter I have taken the cold snow and put in my room at the fire, making it melting. I have also made fire in a tiled stove and put ... a kettle with melting snow together with the thermometer inside the stove. However, I have always found the mercury showing the same point, as long as the snow was tight around the thermometer ball."

He was equally careful with the boiling point, investigating whether the source of water (river, snow, well) or the quality (good water, normally used for making tea) made a difference. He found, now common knowledge, that the boiling point of water depends on atmospheric pressure, and wrote that "From the experiments can be clearly seen that the height of the thermometer in boiling water is always proportional to the height of the barometer. ... And since according to all meteorological observations here in Sweden as well as in other places in Europe, the mean height of the barometer is close to 25 [Swedish decimal] inches and 3 lines [751 mm, corresponding to $1001 \mathrm{hPa}$ ], it is best to choose that point as fixed which the thermometer shows in boiling water when the barometer is at the mentioned height."
The details Ekman has ferreted out throughout the book provide richness for the reader, well exemplified in the temperature scale section. For example, we find out that Celsius' first use of his scale was on Christmas Day 1741 and, for official weather reporting, on 2 June 1743, with a diary note by an assistant that the observations were based on "the experimental thermometer, hereafter called the Celsius one". Ekman notes that the division of the scale into 100 degrees followed adoption of the decimal system in 1739 for both Swedish length units and part of the Swedish monetary system. It is generally unknown, however, that Celsius initially assigned 0 degrees at the boiling point and 100 degrees at the freezing point to avoid negative numbers for commonly experienced temperatures, but the scale was reversed a few years later to the Celsius scale that we know today.

Overall the book makes the point that Celsius was "more than a temperature man". A final chapter lists no fewer than 15 scientific accomplishments made by Celsius and his assistants, including geodesy (the first arc measurements for determining the shape of the Earth, using stars for latitude determination, coastal positioning and marine charting, vertical uplift of coastlines); astronomy (tables of Jupiter's moons); geophysical methods (gravity measurements, air pressure measurements in relation to sea level, temperature scale and unit); climate (the first climate statistics and study of climate change); and magnetism (magnetic changes and their relation to northern lights). An epitaph over Celsius in a church in Uppsala understates his contributions - "Clear sense, honest will, careful work and useful learning".

Martin Ekman's book on Celsius is beautifully produced, has a number of photos of historic instruments, documents, and buildings, and is well worth the 22 Euros to purchase it. Information on how to order the book can be found at www. historicalgeophysics.ax. 